\title{
Parte III \\ Novos desafios do campo da saúde, ambiente e trabalho temas emergentes e abordagens metodológicas
}

\author{
Rita de Cássia Pereira Fernandes \\ Mônica Angelim Gomes de Lima \\ Tânia Maria de Araújo \\ (orgs.)
}

\section{SciELO Books / SciELO Livros / SciELO Libros}

FERNANDES, R.C.P., LIMA, M.A.G., and ARAÚJO, T.M., comps. Novos desafios do campo da saúde, ambiente e trabalho: temas emergentes e abordagens metodológicas. In: Tópicos em saúde, ambiente e trabalho: um olhar ampliado [online]. Salvador: EDUFBA, 2014, pp. 380-382. ISBN: 97865-5630-012-2. https://doi.org/10.7476/9786556300122.0019.

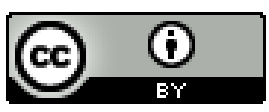

All the contents of this work, except where otherwise noted, is licensed under a Creative Commons Attribution 4.0 International license.

Todo o conteúdo deste trabalho, exceto quando houver ressalva, é publicado sob a licença Creative Commons Atribição $\underline{4.0}$. 


\section{PARTE III}

Novos desafios do campo da saúde, ambiente e trabalho: temas emergentes e abordagens metodológicas 
A amplitude e complexidade das problemáticas emergentes da triangulação saúde, ambiente e trabalho, constantemente atualizadas, refletem múltiplas interações e interrelações entre fenômenos sociais, biológicos, psicológicos, em diferentes contextos econômicos e culturais. Esta dinâmica abre novas frentes de estudo, delineia novos objetos e requer dos pesquisadores a progressiva aproximação de diferentes abordagens teórico-metodológicas.

A necessidade de compreender o comportamento humano na relação com a promoção da saúde, a prevenção de doenças e a experiência do adoecimento crônico tem suscitado investigações sobre possíveis mediadores do processo de tomada de decisão do sujeito na interação com o serviço de saúde e suas influências na relação com os diferentes sistemas sociais, principalmente a família, a comunidade e o trabalho.

Nesta seção são apresentados três trabalhos empíricos que focalizam temas correlatos sobre prevenção, promoção da saúde e contexto familiar e um capítulo que explora o percurso metodológico em um estudo de abordagem etnográfica. Em "Comportamento de industriários quanto à prevenção do câncer da próstata”, os autores exploram as razões para a pouca realização de exames de próstata entre industriários e identificam que, apesar do bom conhecimento sobre a doença, a adesão a essa prática é pequena, embora reconheçam que o aumento da percepção de susceptibilidade, severidade, autoficácia e benefício contribuem com a prevenção. De maneira semelhante, em "Conhecimentos e atitudes sobre câncer de mama e de colo de útero entre trabalhadoras de saúde", os autores discutem os principais motivos que levaram essas profissionais a realizarem a mamografia e o exame de Papanicolaou, bem como as principais barreiras, dentre elas a falta de tempo e o medo de descobrirem a doença. Estes estudos em categorias distintas contribuem para a valorização das ações de promoção à saúde em ambientes de trabalho. Em "O trabalhador-doente e sua família: interações e repercussões sobre o absenteísmo e o processo de retorno ao trabalho", os autores discutem as mudanças na estrutura e função da família em consequência da presença do trabalhador-doente na residência; as mudanças no seu papel social e as interações com o serviço de saúde durante o processo de adoecimento e reabilitação. A literatura revisada atualiza as principais tendências dessa discussão e 
o reconhecimento da importância das diferentes dinâmicas familiares como facilitador ou obstáculo para o retorno ao trabalho.

A presença crescente de abordagens compreensivas neste campo de estudo tem resultado na aproximação com as ciências sociais, marcadamente com a sociologia da saúde e com a antropologia interpretativa, com ênfase, em alguns estudos, na tradição etnometodológica. Em "O percurso etnometodológico de uma pesquisa em Santo Amaro-BA”, os autores discutem a produção do conhecimento e sua interface (ou falta de) com a comunidade afetada. Esta problematização parte do questionamento sobre a distância ou mesmo a dicotomia entre produção do conhecimento e a sua apropriação pelos sujeitos de pesquisa, tomando o caso da contaminação por chumbo em Santo Amaro-Ba. Os sujeitos de estudo - marisqueiras, pescadores e professoras ativos ou aposentados das comunidades de Caeira e São Braz - são convidados a falar. A primeira autora associa sua experiência como jornalista à imersão em campo, produzindo, neste capítulo, um relato ensaístico do percurso metodológico em uma perspectiva autoetnográfica. Toma, portanto, a sua subjetividade, alimentada pela experiência em campo e reflexão teórica, como fundamentos para a interpretação sobre a avaliação e comunicação do risco às comunidades atingidas e a necessidade de novas metodologias para a tomada de decisão sobre riscos ambientais. 